\title{
Unilateral Tubular Approach for Bilateral Laminotomy vs Transforaminal Lumbar Interbody Fusion for Lumbar Spinal Stenosis
}

\section{Bin Lv ( $\nabla$ dr_lvbin@sina.com )}

Zhenjiang First People's Hospital https://orcid.org/0000-0002-4368-0232

\section{Minjie $\mathrm{Hu}$}

Zhenjiang First People's Hospital

\section{Lei Zhang}

Zhenjiang First People's Hospital

\section{Shiqi Bi}

the Affiliated People's Hospital of Jiangsu University

\section{Research article}

Keywords: Minimally invasive surgery, spinal stenosis, lumbar spine, spinal decompression, PEID

Posted Date: July 17th, 2020

DOI: https://doi.org/10.21203/rs.3.rs-41949/v1

License: (c) (i) This work is licensed under a Creative Commons Attribution 4.0 International License. Read Full License 


\section{Abstract}

Background: Endoscopic techniques is considered to be the standard tissue sparing approach for surgical advantages, rapid rehabilitation, and instability prevention. PEID techniques were introduced to treat lumbar spinal stenosis. However, its effectiveness and safety in the treatment of moderate and severe lumbar stenosis is uncertain.

Methods: Between June 2014 and June 2016, patients suffering from lumbar spinal stenosis underwent a bilateral laminotomy through a unilateral tubular approach. Demographics, intraoperative data, and patient-reported outcomes were ascertained

Results:There were no significant differences in patient demographics between the two groups. The statistically significant improvements in leg and back VAS scores were reported on the ipsilateral and the contralateral side ( $p<0.05$, respectively). Analysis of VAS and ODI scores demonstrated no significant differences in improvement on both groups. There were no difference in radiographical and intraoperative outcomes during the follow-up period.

Conclusions: Regarding the intraoperative data, and patient-reported outcomes, the PEID is a safety, and efficacy minimally invasive technique. This observation suggests that the PEID techniques were excellent or showed good results.

\section{Introduction}

Lumbar spinal stenosis (LSS) is caused by discal, bony, ligamentary, or capsular structures. LSS is the most common disease accompanied by nerve compression in the intervertebral foramen, lateral recess, or central vertebral canal, resulting in low back pain, leg pain, or neurogenic claudication ${ }^{1}$. The association between the extent of LSS in imageology examination and the clinical symptoms is unequivocal ${ }^{2}$. Fusion is routinely adopted to limit postoperative instability in patients with $\mathrm{LSS}^{3}$. Adjacent level degeneration caused by instability may result in deterioration of symptoms ${ }^{4,5}$. In therapeutic terms, decompression with instrumented fusion is sufficient in elderly patients meet the indication for lumbar spine surgery ${ }^{6}$. The traditional approach involves bilateral paraspinal muscle dissection, extensive removal of the spinous processes, supraspinous, and interspinous ligaments, wide laminectomy, increasing the incidence of complications such as infection, neurologic deficits, and adjacent segment degeneration ${ }^{7}$. These perioperative complications have been demonstrated to be associated with various problems, such as a prolonged decubation, increased incidence of spinal instability, and increased reoperation rate ${ }^{8}$. Further, failures of operationattribute to paraspinal muscle atrophyand persistent back pain, caused by excessive intraoperative dissection of the paraspinal muscule anddenervation injury ${ }^{9}$.

To overcome these problems following the conventional approach, we adopt the "BUDA with PELD" technique which describes bilateral decompression via a ipsilateral approach to treat $\mathrm{LSS}^{10}$. We present 
here a case series of patients who underwent " BUDA with PELD" procedures for the treatment of severe LSS and assess the clinical outcomes of this procedure.

\section{Methods}

\section{Study Design}

Electronic medical record of 105 patients who underwent a BUDA with PELD and TLIF procedure from June 2014 to June 2017were identified.The basic demographic and clinical data were as follows: age, gender, body mass index (BMI), smoking status, Charlson Comorbidity Index (CCI), chief complaint, surgical levels, comorbidity. This retrospective case study was approved by the ethicalreview committee of our institution (Grant No.K-20190036-W). All patients signed a consent preoperatively for participation in this clinical studyinvolving a BUDA with PELD and TLIF procedure for LSS.All the patients suffered from low back pain were diagnosed with moderate or severe LSS via computed tomography (CT) scans and magnetic resonance imaging (MRI). The main cause of back pain was identified by a CT scan and whether the back pain was caused by symptomatic LSS was determined by an MRI examination. The operations were performed by two surgeons with abundant experience in lumbar surgery.

\section{Data Collection}

Questions were asked to patients or their relatives over the phone and spine surgeons from our institutions completed the outcome measurements for them. Primary outcome included the Visual Analogue Scale (VAS),Oswestry Disability Index (ODI) and the modified Macnab Criteria(Macnab) weremeasured to patients preoperatively and postoperatively during the follow-up period. In addition, the estimated blood loss, procedure duration, and perioperative adverse events were evaluated. Secondary outcome including the incision size, the time for ambulation, and the time for hospitalization.

\section{Operative Procedure}

All patients were treated by the standard procedures. The procedures were performed successfully under the guidance of a $\mathrm{C}$-arm angiographic unit in all patients. The patients were placed on the operating table in a beach-chair position under cervical plexus block anesthesia or general anesthesia.Patients were positioned prone on a Jackson table. Under general anesthesia, a 2-cm skin incision was made overlying the target level on the posterior approach in a midline of back. Unilateral tubular approach for bilateral laminotomy, as described by as Alimi et al. ${ }^{11}$, was performed. The inferior edge of the lamina and the inferior edge and base of the spinous process were exposed. Then Ausculap channel expander was inserted.Removal of the thickened lamina with a $5 \mathrm{~mm}$ diameter grinding brick under micromanipulation. When the lamina became thinner, a $5 \mathrm{~mm}$ diameter diamond bricks was used to remove the residual bone structure.(Figure1)

A step by step decompression was performed starting with an ipsilateral partial laminotomy, using a bayonetted 2 and $3 \mathrm{~mm}$ Kerrisson punches. The tubular retractor was angled mediallyand the microscope 
and operating table were tilted tilting to the affected side to get clearer visualization of contralateral sublaminar structures. Then, the basal part of spinous process was removed using the drill. Neural root dissector protects dura and contralateral nerve roots and contralateral lamina was removed by a Kerrisson rongeur.Meticulous and complete decompression of the contra lateral recess and removal of the yellow ligament was accomplished. The final step was returning the table and retractor to the initial position and completion of the ipsilateral decompression.(Figure2)

\section{Statistics}

Summary statistics reported as mean \pm standard deviation (SD). The demographic and surgical variables between the two groups were compared by univariate analysis. In addition, the categorical variables were tested by Fisher's exact test and the continuous variables were tested by Mann-Whitney test.The statistical significance level was $\mathrm{P}<0.05$.

\section{Results}

A total of 25 patients underwent BUDA with PELD and 53 patients underwent TLIF were retrospectively analysed. No significant differences was found between the two groups with respect to age, gender, BMI and steroid medication and prior smoking history $(p>0.05$, Table 1$)$. The BUDA with PELD group had significantly lower procedure duration, estimated blood loss and length of hospitalization than TLIF group ( $\mathrm{p}<0.05$, Table 2). No significant differences were found in complications or reoperations at 1-year follow-up between both groups. No serious intraoperative complications, including cerebrospinal fluid leakage, spinal cord injury, were observed. In addition, no significant difference was observed in terms of anteroposterior diameter of spinal canal, spinal canal area, and adjacent segment disease. CT examination showed that lumbar spinal canal had been expanded by the surgery procedure, and we observed no sinking lamina or broken shaft. An MRI examination revealed that high signal intensity of the spinal cord decreased and no further spinal cord compressions. The MRI of radiological examinations shows canal size of lumbar spine between preoperative to postoperative late following-up.All patients reported significant improvement in neurological deficits within 2 weeks postoperationly.

The average VAS score, ODI score, and the Macnab showed a significant improvement at different time point postsurgery, showing satisfactory outcomes. However, table 3 indicated that no significant difference in VAS score and ODI score was found between the two groups in different follow-up time period $(P>0.05$, Table 3$)$.

Table 1 Demographics details of the patients with LSS 


\begin{tabular}{|llll|}
\hline Items & PEID 25 & TLIF 53 & P Value \\
\hline Age & 63.5 & 62.7 & $>0.05$ \\
\hline Gender(male/female) & $12 / 25$ & $27 / 53$ & $>0.05$ \\
\hline BMI (kg/m2) & $24.16 \pm$ & $24.16 \pm$ & $>0.05$ \\
\hline Smoker & 2 & 5 & $>0.05$ \\
\hline Steroid medication & 2 & 5 & $>0.05$ \\
\hline Chief Complaint & & & $>0.05$ \\
\hline Back pain & 23 & 47 & \\
\hline Neurogenic Claudication & 21 & 44 & \\
\hline Radiculopathy & 21 & 48 & \\
\hline Surgical level & & & $>0.05$ \\
\hline L2/L3 & 1 & 3 & \\
\hline L3/L4 & 4 & 7 & \\
\hline L4/L5 & 18 & 39 & \\
\hline L5/S1 & 2 & 4 & \\
\hline Comorbidity & & & \\
\hline Hypertension & 11 & 21 & \\
\hline Diabetes mellitus & 3 & 7 & \\
\hline Cardiovascular disease & 2 & 5 & \\
\hline
\end{tabular}

Table 2 Intraoperative data and 2-year follow-up data

\begin{tabular}{|llll|}
\hline Items & PEID & TLIF & P Value \\
\hline Procedure duration $(\mathrm{min})$ & 114.2 & 148.5 & $<0.05$ \\
\hline Estimated blood loss $(\mathrm{mL})$ & 4.24 & 432 & $<0.05$ \\
\hline Length of hospitalization (d) & 8.16 & 10.16 & $<0.05$ \\
\hline Anteroposterior diameter of spinal canal & 110.32 & 121.42 & $>0.05$ \\
\hline Spinal canal area & 10.90 & 13.45 & $>0.05$ \\
\hline Adjacent segment disease & 2 & 5 & $>0.05$ \\
\hline
\end{tabular}


Table 3 Changes in clinical outcomes from baseline

\begin{tabular}{|llll|}
\hline Items & PEID & TLIF & P Value \\
\hline Leg pain VAS & & & \\
\hline Baseline & $3.4 \pm 1.1$ & $3.6 \pm 1.1$ & $>0.05$ \\
\hline 3 mo & $0.6 \pm 0.3$ & $0.7 \pm 0.3$ & $>0.05$ \\
\hline 12 mo & $0.3 \pm 0.1$ & $0.3 \pm 0.1$ & $>0.05$ \\
\hline Low back pain VAS & & & \\
\hline Baseline & $3.4 \pm 1.2$ & $3.6 \pm 1.5$ & $>0.05$ \\
\hline 3 mo & $0.6 \pm 0.3$ & $0.7 \pm 0.3$ & $>0.05$ \\
\hline 12 mo & $0.3 \pm 0.1$ & $0.6 \pm 0.3$ & $>0.05$ \\
\hline ODI Score & & & \\
\hline Baseline & $42.1 \pm 9.2$ & $41.3 \pm 8.7$ & $>0.05$ \\
\hline 3 mo & $23.1 \pm 4.3$ & $20.1 \pm 3.9$ & $>0.05$ \\
\hline 12 mo & $20.4 \pm 4.1$ & $18.1 \pm 3.7$ & $>0.05$ \\
\hline
\end{tabular}

\section{Discussion}

Lumbar spinal stenosis (LSS) is one of the most frequent etiologies of chronic back pain, neurogenic claudication, and lumbar radiculopathy. Bilateral dissection and retraction of the paraspinal muscles, wide laminectomy, medial facetectomy and foraminotomy were traditional decompression strategy involved in treatment of LSS. Excessive disruption of supraspinous/interspinous ligament complex and posterior bony contribute to spinal instability, which eventually increase the rate of surgical failures and revision surgery ${ }^{12,13}$. Meanwhile, minimally invasive laminectomy approaches have been widely recognized to be associated with decreased approach related morbidity.

Eventhough PEID was associated with less blood loss, narcotic use, and satisfactory clinical outcomes in previous studies. However, there is a lack of clinical evidence to comfirm its safety and efficacy comparing PEID to TLIF. The current study shows that ULBD technique is a viable option for patients with moderate and severe LSS ${ }^{14}$. Absence of muscle dissection with the endoscope and instruments over the lamina and preservation of the soft tissue structures, could alleviate the muscle atrophy and spinal instability ${ }^{15}$. Furthermore, another advantage of ULBD lies in its mitigation the risk of adjacent segment fusions postoperative, while adjacent segment disease following fusion involves fusing a second level in 
traditional revision surgery ${ }^{16}$.Also, the reduction in duration of hospitalization was observed.The complication rates in the literature for TLIF have an average of $36,7 \%$, whereas minimally invasive laminectomy approaches have $28,4 \%{ }^{17}$. The present study found that patients underwent PEID approach show good clinical outcomes and pain scores at 3 and 12 months after operation. Even though decompression with instrumented fusion was widely used in the past, clinical experience demonstrate that decompression alone can lead to satisfactory patient-reported outcomes ${ }^{18}$.Complex MIS surgeries, such as microdiscectomy, transforaminal lumbar interbody fusion, are built on the foundation of simple laminotomy. At present, there is no consensus providing a treatment algorithm for LSS due to sagittal imbalance and severity of stenosis. While there is sort of a big academic debate on surgical indications of fusion for LSS, TLIF was proven to be improve lumbar function and spinal stabilization ${ }^{3,19}$. TLIF allow weight-bearing through the anterior column and would prevent the stress concentration that may increase the instability of the adjacent vertebra 20,21 .

PEID was reported to treat several degenerative lumbar disease, such as degenerative scoliosis and spondylolisthesis, lumbar stenosis, and thoracic disc herniations ${ }^{14,22,23}$. Previous reports have already demonstrated that ULBD is a effective and safe approach to treat degenerative spondylolisthesis ${ }^{10}$.Several clinical study focused attentionon the clinical efficacy of ULBD for the treatment of severe lumbar stenosis. Komp et $\mathrm{al}^{24}$ conducted a prospective, randomized, controlled research and demonstrated that full-endoscopic ULBD is an is safe and effective strategy for treating LSS. In this study, 71 patients demonstrated constantly and obviously improved back pain and leg pain and daily activities. even though slight deterioration was observed.No patient suffered worsening of back pain. Postoperative pain symptom and analgesics, such as ibuprofen and paracetamol, show significant improvement.Furthermore, the rate of complications related to the procedure was significantly reduced during the follow-up. The maximum duration of hospitalization was shortened as a result of using the full-endoscopic technique. Referring to complications, we found the incidence of dural tears increased slightly in the in the ULBD group. Mobbs et al. showed that incidental durotomy rates was $3.7 \%$ in ULBD group and open surgery group ${ }^{25}$, whereas incidence of dural tears in classic laminectomy may range from $5 \%$ to $15 \%{ }^{26}$. Only 1 incidental durotomy happened in our study and we found it challenging to identificate and suture the dural tears through a smaller surgical channel. In addition, postoperative lumbar instability was not observed in the PEID group. This study confirm that length of hospitalization and estimated blood loss were less in our operation, which is consist with the previous literature.

When it comes to clinical outcomes, the success rate demonstrated no significant difference between the 2 groups, although a slightly better patient-reported outcome after PEID can be seen; in the long term, PEID showed equally effection in improving pain and function when compared to fusion. ULBD facilitates neural decompression while preserving stabilizing osseoligamentous structures and may be uniquely suited for the treatment of LSS with concurrent mild to moderate degenerative deformity. Thus, the main advantages of this less invasive technique lie in the reduction of postoperative instability and more suitable for patients with lumbar spinal stenosis and severe osteoporosis. This study found that PEID did not have any advantage in patient-reported outcomes compared with TLIF techniques after surgery. 
Additionally, this surgical procedure can be an effective treatment of other degenerative lumbar diseases.Thoracic disc herniations were first reported by Yüce et $\mathrm{al}^{23}$ to be alleviatied by ULBD approach. A previous study reported that patients with thoracic disc herniation should undergo fusion ${ }^{27}$. However, fusion surgery inflicts traumatic injury than ULBD, leading to a longer hospitalization. Other methods, such as physical therapy, medication treatment, and nerve root block could ease the back pain caused by

disc herniation ${ }^{28,29}$. We strongly recommended PEID to alleviate pain if the conservative treatment has no any effect on patient.

Some limitations should be addressed in current study. First, this retrospectively study has less creditability. Hence, future prospective studies should be performed to evaluate the effectiveness and safety of the PEID procedure. Second, only 10 patients, a small sample size, were enrolled in this study, which makes the results inaccurate. Third, patients who underwent PEID procedure were not compared with control procedure in this study.

\section{Conclusions}

Our study demonstrated that PEID approach is an effective procedure for treatment of lumbar stenosis (LSS). The results of the present study demonstrated that patients underwent PEID procedure showed effective pain relief and functional improvement throughout the medium-term follow-up. Besides, there were no complications and the improvement in patient pain continued throughout the long-term followup. Large-scale prospective studies are required to assess the effectiveness of PEID procedure in the treatment of elderly patients with moderate to severe LSS. Most surgeons familiar with the procedure agree that the PEID approach appears to afford a more complete decompression of the contralateral thecal sac and nerve root, as compared to the ipsilateral approach, reducing iatrogenic injury of bone and soft tissue. Further, open surgery is recommended as a secondary approach if PEID procedure has proven unsuccessful.

\section{Abbreviations}

LSS: lumbar stenosis; PEID: percutaneous endoscopic lumbar discectomy; CT: computed tomography

\section{Declarations}

\section{Acknowledgements}

None.

\section{Ethics approval and consent to participate}

This study was approved by the ethics committee of Nanjing Drum Tower Hospital affiliated to the Medical School of Nanjing University. 


\section{Consent for publication}

All the patients in this study have given their informed consent for the article to be published.

\section{Availability of data and materials}

The data used to support the findings of this study are included within the article.

\section{Conflict of interest}

On behalf of all authors, the corresponding author states that there is no conflict of interest.

\section{Funding}

This study was sponsored by the Clinical Medicine Science and Technology Development Foundation of Jiangsu University (Grant No: JLY20180047) and the Clinical Medicine Science and Technology Development Foundation of Jiangsu University (Grant No: JLY20180271).

\section{Authors' contributions}

$\mathrm{BL}$ and $\mathrm{MJH}$ conceived and designed the study. $\mathrm{MJH}$ and $\mathrm{LZ}$ collected the data. SQB performed the statistical analysis. BL and MJH wrote the manuscript. All authors read and approved the final manuscript.

\section{References}

1. Thomas K, Faris P, Mclntosh G, Manners S, Abraham E, Bailey CS, Paquet J, Cadotte D, Jacobs WB, Rampersaud YR, Manson NA, Hall H, Fisher CG. Decompression Alone vs Decompression plus Fusion for Claudication Secondary to Lumbar Spinal Stenosis. Spine J. 2019

2. Torgerson WR, Dotter WE. Comparative roentgenographic study of the asymptomatic and symptomatic lumbar spine. J Bone Joint Surg Am. 58:850-853, 1976

3. Farrokhi MR, Yadollahikhales G, Gholami M, Mousavi SR, Mesbahi AR, Asadi-Pooya AA. Clinical Outcomes of Posterolateral Fusion vs. Posterior Lumbar Interbody Fusion in Patients with Lumbar Spinal Stenosis and Degenerative Instability. Pain physician. 21:383-406, 2018

4. Soliman MAR, Ali A. Decompression of lumbar canal stenosis with a bilateral interlaminar versus classic laminectomy technique: a prospective randomized study. Neurosurg Focus. 46:E3, 2019

5. Meng FZ, Gao Q, Wang XL, He Y. [Case control study of interbody fusion with simple decompression bone block in treating degenerative lumbar instability and spinal stenosis]. Zhongguo Gu Shang. 30:400-405, 2017

6. Weinstein JN, Lurie JD, Tosteson TD, Hanscom B, Tosteson AN, Blood EA, Birkmeyer NJ, Hilibrand AS, Herkowitz H, Cammisa FP, Albert TJ, Emery SE, Lenke LG, Abdu WA, Longley M, Errico TJ, Hu SS. 
Surgical versus nonsurgical treatment for lumbar degenerative spondylolisthesis. The New England journal of medicine. 356:2257-2270, 2007

7. Weiner BK, Fraser RD, Peterson M. Spinous process osteotomies to facilitate lumbar decompressive surgery. Spine. 24:62-66, 1999

8. Alimi M, Hofstetter CP, Pyo SY, Paulo D, Hartl R. Minimally invasive laminectomy for lumbar spinal stenosis in patients with and without preoperative spondylolisthesis: clinical outcome and reoperation rates. J Neurosurg Spine. 22:339-352, 2015

9. Leinonen V, Maatta S, Taimela S, Herno A, Kankaanpaa M, Partanen J, Hanninen O, Airaksinen O. Paraspinal muscle denervation, paradoxically good lumbar endurance, and an abnormal flexionextension cycle in lumbar spinal stenosis. Spine. 28:324-331, 2003

10. Mayer HM, List J, Korge A, Wiechert K. [Microsurgery of acquired degenerative lumbar spinal stenosis. Bilateral over-the-top decompression through unilateral approach]. Orthopade. 32:889-895, 2003

11. Alimi M, Hofstetter CP, Torres-Campa JM, Navarro-Ramirez R, Cong G-T, Njoku I, Härtl R. Unilateral tubular approach for bilateral laminotomy: effect on ipsilateral and contralateral buttock and leg pain. European Spine Journal. 26:389-396, 2016

12. Goel A, Ranjan S, Shah A, Patil A, Vutha R. Lumbar canal stenosis: analyzing the role of stabilization and the futility of decompression as treatment. Neurosurg Focus. 46:E7, 2019

13. Mendenhall SK, Parker SL, Adogwa O, Shau DN, Cheng J, Aaronson O, Devin CJ, McGirt MJ. Longterm outcomes after revision neural decompression and fusion for same-level recurrent lumbar stenosis: defining the effectiveness of surgery. Journal of spinal disorders \& techniques. 27:353-357, 2014

14. Kuo CC, Merchant M, Kardile MP, Yacob A, Majid K, Bains RS. In Degenerative Spondylolisthesis, Unilateral Laminotomy for Bilateral Decompression Leads to Less Reoperations at 5 Years When Compared to Posterior Decompression with Instrumented Fusion: A Propensity Matched Retrospective Analysis. Spine. 2019

15. Alimi M, Njoku I, Jr., Cong GT, Pyo SY, Hofstetter CP, Grunert P, Hartl R. Minimally invasive foraminotomy through tubular retractors via a contralateral approach in patients with unilateral radiculopathy. Neurosurgery. 10 Suppl 3:436-447; discussion 446-437, 2014

16. Shin EK, Kim CH, Chung CK, Choi Y, Yim D, Jung W, Park SB, Moon JH, Heo W, Kim SM. Sagittal imbalance in patients with lumbar spinal stenosis and outcomes after simple decompression surgery. Spine J. 17:175-182, 2017

17. Epstein NE. Lower complication and reoperation rates for laminectomy rather than MI TLIF/other fusions for degenerative lumbar disease/spondylolisthesis: A review. Surg Neurol Int. 9:55, 2018

18. Vaccaro AR, Garfin SR. Degenerative lumbar spondylolisthesis with spinal stenosis, a prospective study comparing decompression with decompression and intertransverse process arthrodesis: a critical analysis. Spine. 22:368-369, 1997 
19. Thomas K, Faris P, Mclntosh G, Manners S, Abraham E, Bailey CS, Paquet J, Cadotte D, Jacobs WB, Rampersaud YR, Manson NA, Hall H, Fisher CG. Decompression alone vs. decompression plus fusion for claudication secondary to lumbar spinal stenosis. Spine J. 2019

20. Lai PL, Chen LH, Niu CC, Fu TS, Chen WJ. Relation between laminectomy and development of adjacent segment instability after lumbar fusion with pedicle fixation. Spine. 29:2527-2532; discussion 2532, 2004

21. Chin KR, Reis MT, Reyes PM, Newcomb AG, Neagoe A, Gabriel JP, Sung RD, Crawford NR. Stability of transforaminal lumbar interbody fusion in the setting of retained facets and posterior fixation using transfacet or standard pedicle screws. Spine J. 15:1077-1082, 2015

22. Phan K, Mobbs RJ. Minimally Invasive Versus Open Laminectomy for Lumbar Stenosis. Spine. 41:E91-E100, 2016

23. Yuce I, Kahyaoglu O, Cavusoglu HA, Cavusoglu H, Aydin Y. Midterm outcome of thoracic disc herniations that were treated by microdiscectomy with bilateral decompression via unilateral approach. J Clin Neurosci. 58:94-99, 2018

24. Komp M, Hahn P, Oezdemir S, Giannakopoulos A, Heikenfeld R, Kasch R, Merk H, Godolias G, Ruetten S. Bilateral spinal decompression of lumbar central stenosis with the full-endoscopic interlaminar versus microsurgical laminotomy technique: a prospective, randomized, controlled study. Pain physician. 18:61-70, 2015

25. Mobbs RJ, Li J, Sivabalan P, Raley D, Rao PJ. Outcomes after decompressive laminectomy for lumbar spinal stenosis: comparison between minimally invasive unilateral laminectomy for bilateral decompression and open laminectomy: clinical article. J Neurosurg Spine. 21:179-186, 2014

26. Castro-Menendez M, Bravo-Ricoy JA, Casal-Moro R, Hernandez-Blanco M, Jorge-Barreiro FJ. Midterm outcome after microendoscopic decompressive laminotomy for lumbar spinal stenosis: 4-year prospective study. Neurosurgery. 65:100-110; discussion 110; quiz A112, 2009

27. Liao CH, Wu JC, Huang WC, Wang WH, Chang PY, Cheng H, Yang S. Endoscope-assisted minimally invasive transforaminal thoracic interbody fusion. Neurosurg Focus. 35:Video 11, 2013

28. Lee JH, Choi KH, Kang S, Kim DH, Kim DH, Kim BR, Kim W, Kim JH, Do KH, Do JG, Ryu JS, Min K, Bahk SG, Park YH, Bang HJ, Shin KH, Yang S, Yang HS, Yoo SD, Yoo JS, Yoon KJ, Yoon SJ, Lee GJ, Lee SY, Lee SC, Lee SY, Lee IS, Lee JS, Lee CH, Lim JY, Han JY, Han SH, Sung DH, Cho KH, Kim SY, Kim HJ, Ju W. Non-surgical treatments for patients with radicular pain from lumbosacral disc herniation. Spine J. 2019

29. Lee JH, Shin KH, Park SJ, Lee GJ, Lee CH, Kim DH, Kim DH, Yang HS. Comparison of Clinical Efficacy Between Transforaminal and Interlaminar Epidural Injections in Lumbosacral Disc Herniation: A Systematic Review and Meta-Analysis. Pain physician. 21:433-448, 2018

\section{Figures}




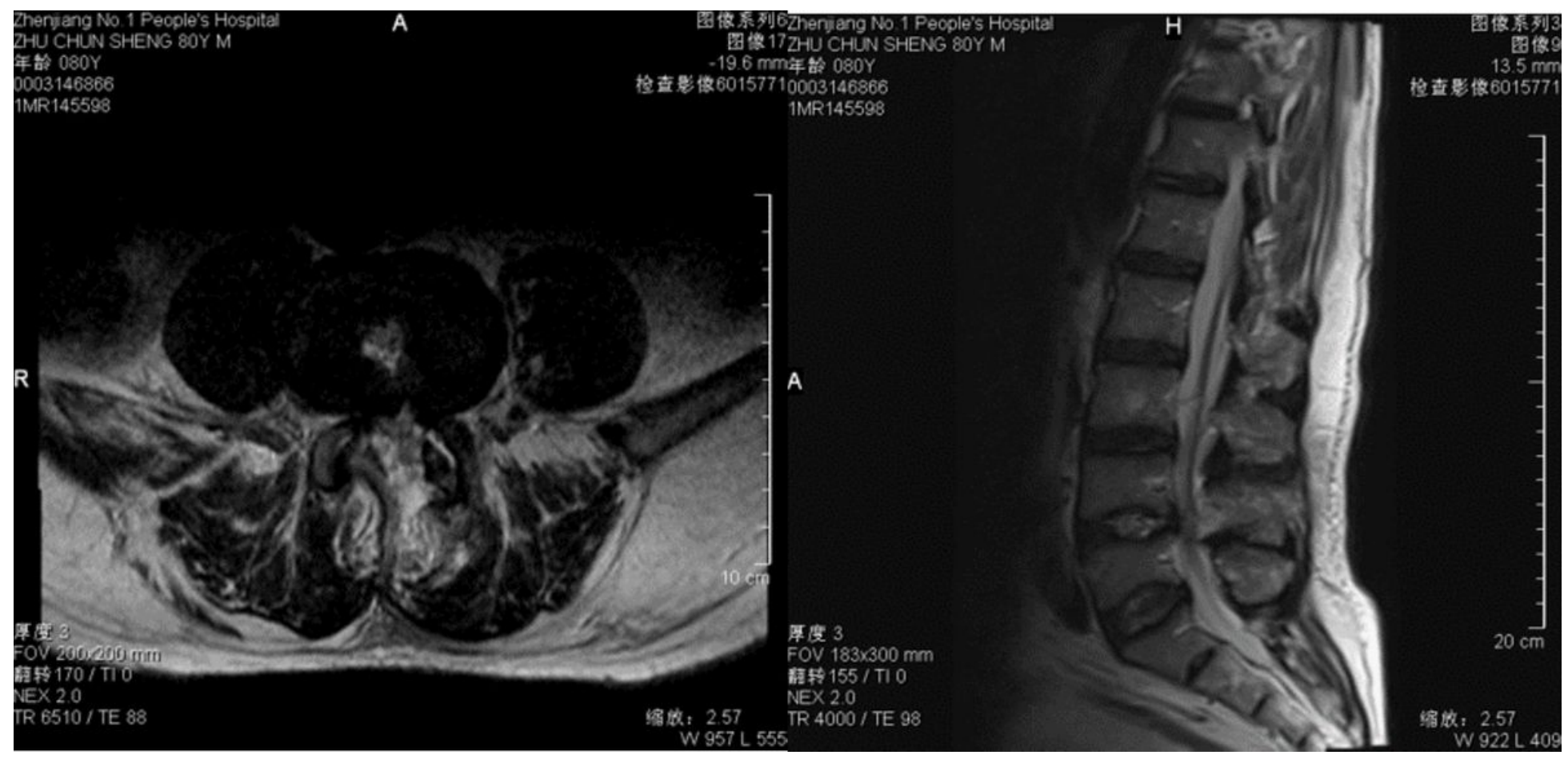

Figure 1

An80-year-old woman with lumbar spinal stenosis. (A) Preoperative MRI shows the severe central canal stenosis of L4-5. (B) Postoperative MRI shows that central canal is widened after PEID.

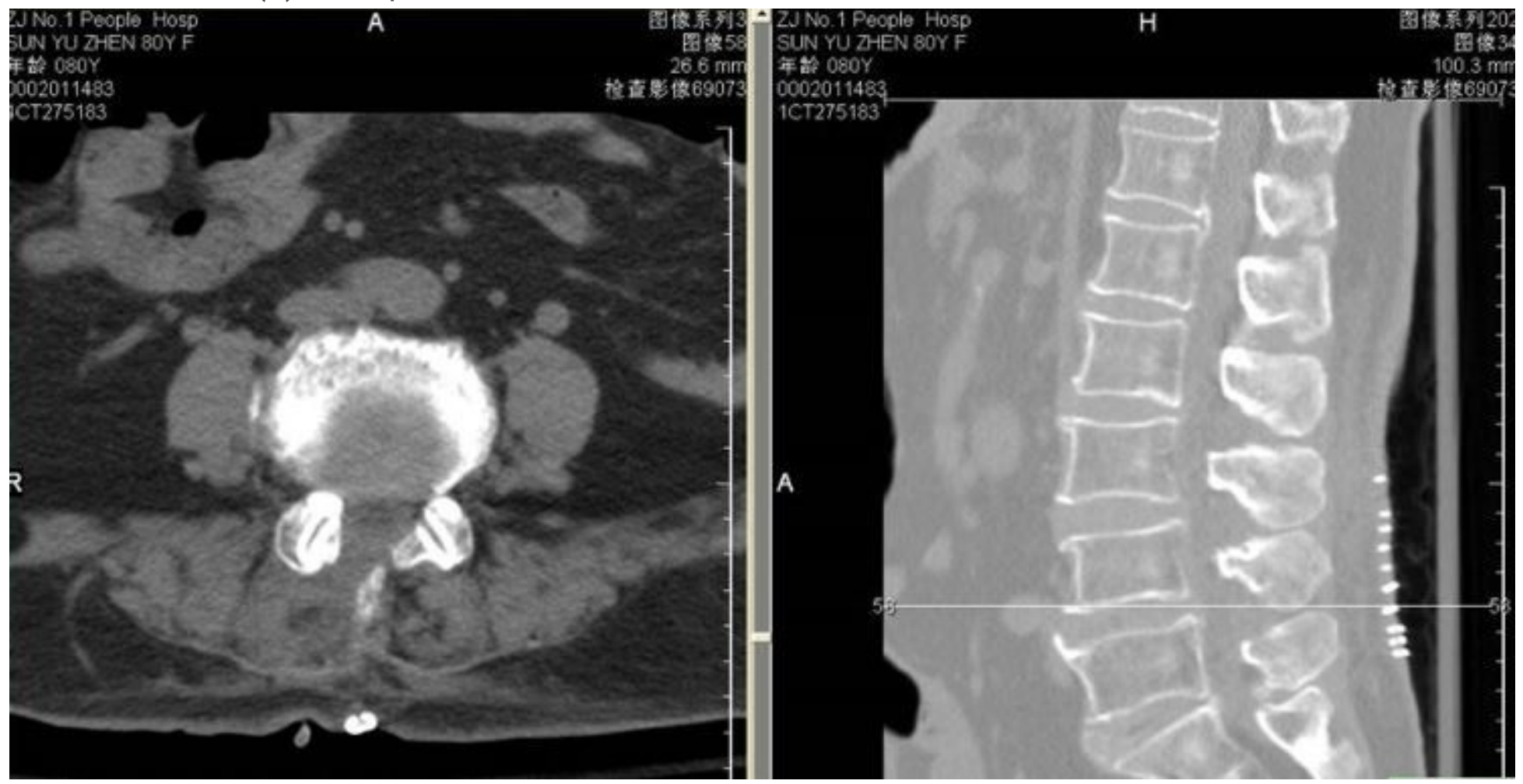

\section{Figure 2}

A typical80-year-old female patient who underwent L4-5 ULBD. 